\title{
Gene therapy for cystic fibrosis: steady progress, should do well
}

\author{
E.W.F.W. Alton*, D.M. Geddes
}

In the early 1990s, when clinical gene therapy trials were initiated for a number of diseases, including cystic fibrosis $(\mathrm{CF})$, there was great expectation both amongst the general public and in some quarters of the scientific and medical profession that this new form of treatment would revolutionize medicine. Recently, a number of articles have been published, with respect to a spectrum of diseases, showing less than encouraging data with regard to such trials [1-5]. This has been accompanied by a flurry of adverse publicity for gene therapy. The aim of this editorial is to suggest that neither the initial overexpectation, nor the present downturn of opinion, have been justified in considering this new form of treatment. It is well-recognized that a new therapeutic product takes a decade or longer to move from the laboratory to the patient. Gene therapy for CF has had a life span of only half this time, and is already in phase I clinical trials. We would suggest that the pace of progress has, in fact, been exceptional in this field, and it is likely that this will continue to be the case, if not distracted by unreasonable expectations or predictable downturns.

Initial studies in vitro $[6,7]$, and subsequently in animal models in vivo $[8,9]$, have demonstrated the feasibility of gene therapy for $\mathrm{CF}$. Whilst a number of vector systems are available to allow expression of a normal copy of the cystic fibrosis transmembrane (conductance) regulator (CFTR) gene, two (adenoviruses and cationic liposomes) have received particular attention. At present, only the lungs have been the target of gene therapy trials, which is understandable in the light of the morbidity and mortality related to this organ. Suitable assays to measure the success or otherwise of such gene transfer studies have been developed, focusing both on detection of messenger ribonucleic acid (mRNA) and protein, as well as more specific assays for CFTR function. The former have relied on conventional polymerase chain reaction (PCR) and immunohistochemistry techni-ques. The latter relate to the properties of this protein as a chloride channel in the apical membrane of the respiratory epithelium. This function can be measured both in vivo and in vitro to provide an assay for the efficacy of gene transfer.

So far, four phase I clinical trials have been reported in the literature, three using adenovirus $[5,10,11]$, and one using cationic liposome [12]. At least a further seven trials are under way or have recently been completed.

Ion Transport Unit, Thoracic Medicine, Imperial College School of Medicine, National Heart and Lung Institute, London.

*Correspondence: E. Alton, Ion Transport Unit, Thoracic Medicine, Imperial College School of Medicine, National Heart and Lung Institute, Manresa Road, London SW3 6LR, UK.
The adenoviral trials have focused predominantly on the nose but have also included the lung, whilst those using liposomes have so far studied only the nasal epithelium. The reason for the focus on the nose, an organ not predominantly affected in $\mathrm{CF}$, is that it provides easier access both for gene transfer and for measurements, demonstrates the bioelectric abnormality characteristic of the disease, and represents an organ that is likely to be safer for assessment of potential toxicity. The overall picture emerging from these studies is that, in the nasal epithelium, approximately $50 \%$ of subjects demonstrate the presence of either mRNA or protein produced as a result of transfer of a normal copy of the CFTR gene. With regard to the important functional endpoints, approximately one third of patients can be shown to demonstrate a degree of correction of the chloride abnormality. With respect to safety, very few problems have been encountered in the nasal epithelium. Importantly, these conclusions are valid both for the adenoviral and liposome-mediated trials, with very similar data. One interim conclusion, therefore, is that in vivo in the nasal epithelium neither system appears to outstrip the other with respect to these characteristics.

With regard to the lower airways, the number of patients demonstrating successful gene transfer, as measured by assessment of mRNA or protein, is somewhat less than for the nasal epithelium, the former being around $30 \%$. At the present time, no study has assessed functional correction in the lung because of the lack of a suitable assay for electrical measurements in this part of the respiratory tract. As noted previously, it is only adenoviral trials that have reached this portion of the respiratory tree, and with regard to safety it is clear that there is a dose-dependent toxic response related, in part, to cytotoxic T-lymphocytes and the production of cytokines. It is, perhaps, worth noting that delivery to the lung has been either by nebulization or direct bronchoscopic instillation. The latter will encourage peripheral pooling, with an increased potential for dose-related damage.

Given the cloning of the CFTR gene in 1989, we consider this bank of data to represent substantial and rapid progress. Nevertheless, and not surprisingly, it is clear that many problems exist. Firstly, gene transfer efficiency is not high in vivo. Perhaps the most important question relating to this is: How much is enough? Two sets of experiments have been undertaken to try and address this issue. Firstly, if we assume that in a monolayer of epithelial cells only a limited number will be transfected, BOUCHER and co-workers [13] demonstrated that transfection of approximately $6-10 \%$ of a monolayer of CF cells with a normal copy of the CFTR gene 
produces maximal correction of the chloride abnormality of the whole sheet of cells. Secondly, if we assume that all cells are transfected but to very low levels, our own studies have demonstrated that approximately $5 \%$ of normal CFTR mRNA is sufficient to correct the electrical abnormality in CF mouse models [14]. This relates to the nonlinear relationship between CFTR mRNA and CFTR function, with, effectively, a small quantity of mRNA producing large changes in chloride transport and, in turn, in alterations in pathology. This finding is in agreement with hypothetical considerations for an autosomal recessive disease. Both these studies give cause for guarded optimism and, perhaps, suggest that even with low levels of transfection it may be possible to produce clinical benefit.

The second key issue relates to possible toxicity. Attention has focused, in particular, on the adenoviral systems, given the documented dose-dependent problems described above. Again these problems are predictable in light of the body's response to a viral infection, and a great deal of effort is being invested to reduce the immunogenicity of newer generation adenoviral vectors. This includes deletions of increasingly large regions of the adenoviral genome, as well as attempts at manipulating the immune system. So far, cationic liposomes have not run into major problems, but clearly if enough of a compound is deposited in the lungs, toxicity will eventually ensue. In preparation for a lung trial using cationic liposome, we have recently studied the effect of the Genzyme lipid \#67, in five increasing doses nebulized into the lungs of normal volunteers, without noting any safety problems.

A third issue relates to duration of expression and the need for repeated application, a feature both of liposomal and adenoviral-mediated delivery. The typical time course for expression of the protein of perhaps a week or so [12] has sometimes attracted critical comment. This time course, in part, relates to the episomal nature of these vector systems and the lack of stable integration into the genome. Again, it is important to place these data in the context of conventional pharmacological agents, often given up to four times daily in CF patients. Furthermore, the episodic nature of this delivery may be a valuable safety feature, allowing treatment to be started and stopped as required; the lack of integration, with the potential for unknown mischief, is to be welcomed. Set against this is the need for repeated successful expression, and this may, in particular, be a problem for the adenoviral systems. It is clear from a number of studies that neutralizing antibodies to the adenoviral coat protein are produced, and this is in inverse relationship to the efficiency of gene expression. Again, a great deal of effort is being put into solving this problem in a number of laboratories.

Clearly, it is the lung that requires treatment and it will be important to have assay systems for measuring the efficiency of CFTR expression within this organ. To this extent, we have recently undertaken measurements of lower airway potential difference (an index of chloride channel function) both in $\mathrm{CF}$ and non-CF subjects, demonstrating that these two groups can be clearly discriminated on the basis of this measurement. Furthermore, we and other groups, are demonstrating the usefulness of fluorescent and other intracellular indicators that can be loaded into epithelial cells, removed from the patient, and assayed for the efficiency of gene transfer ex-vivo in the laboratory [15-16]. Finally, a number of groups have reported that increased bacterial binding or viability within the respiratory tract is characteristic of CF tissues [17-19], and this may provide a further assay system within the lower respiratory tract.

Another important and, perhaps, unexpected outcome of such gene therapy studies has been the need for academic groups to liaise with industry. It has rapidly become clear that, given the need for screening of a large number of gene transfer agents, the communication with regulatory and ethics bodies and, finally and importantly, the production of large quantities both of plasmid deoxyribonucleic acid (DNA) and gene transfer agents are beyond the scope of academia. This has produced an important and interesting merger of academia and industry, which, although initially perhaps difficult, has probably benefited both. In this sense, gene therapy for cystic fibrosis can be seen as a pathfinder for a number of other diseases to which this new technique is potentially applicable. This is also the case for many scientific aspects, for example elucidating the formulations of DNA and liposomes needed for successful delivery to the lung, and the development of suitable clinical protocols to assess the safety and efficacy of these studies [20]. We would, therefore, conclude that, contrary to the present downturn of opinion with respect to gene therapy, progress with cystic fibrosis has been rapid, encouraging and exciting. It is, and always was, an unrealistic dream that 5 yrs on from the cloning of the gene patients would be receiving benefit from this form of treatment. Present problems are predictable, and are likely to be soluble, given the effort being undertaken in numerous laboratories worldwide. Rather than the gloomy and, perhaps, rather dramatic coverage that gene therapy has recently received, we would suggest that the present report should read: "Steady progress, should do well".

\section{References}

1. Grossman M, Rader DJ, Muller DWM, et al. A pilot study of ex-vivo gene therapy for homozygous familial hypercholesterolemia. Nat Med 1995; 1: 1148-1154.

2. Blaese RM, Culver KW, Miller AD, et al. T-lymphocyte-directed gene therapy for ADA-SCID: initial trial results after 4 years. Science 1995; 270: 475-479.

3. Bordignon $\mathrm{C}$, Notarangelo LD, Nobili N, et al. Gene therapy in peripheral blood lymphocytes and bone marrow for ADA-immunodeficient patients. Science 1995; 270: 470-474.

4. Mendell JR, Kissel JT, Amato AA, et al. Myoblast transfer in the treatment of Duchenne's muscular dystrophy. $N$ Engl J Med 1995; 333: 832-838.

5. Knowles MR, Hohneker KW, Zhou Z, et al. A controlled study of adenoviral vector-mediated gene transfer in the nasal epithelium of patients with cystic fibrosis. N Engl J Med 1995; 333: 823-831.

6. Drumm ML, Pope HA, Cliff WH, et al. Correction of the cystic fibrosis defect in vitro by retrovirus-mediated gene transfer. Cell 1990; 62: 1227-1233.

7. Rich DP, Anderson MP, Gregory RJ, et al. Expression of cystic fibrosis transmembrane conductance regulator corrects defective chloride regulation in cystic fibrosis airway epithelial cells. Nature 1990; 347: 358-363. 
8. Hyde SC, Gill DR, Higgins CF, et al. Correction of ion transport defect in cystic fibrosis transgenic mice by gene therapy. Nature 1993; 362: 250-255.

9. Alton EW, Middleton PG, Caplen NJ, et al. Noninvasive liposome-mediated gene delivery can correct the ion transport defect in cystic fibrosis mutant mice. Nat Genet 1993; 5: 135-142.

10. Zabner J, Couture LA, Gregory RJ, Graham SM, Smith $\mathrm{AE}$, Welsh MJ. Adenovirus-mediated gene transfer transiently corrects the chloride transport defect in nasal epithelia of patients with CF. Cell 1993; 75: 207-216.

11. Crystal RG, McElvaney NG, Rosenfeld MA, et al. Administration of an adenovirus containing the human CFTR cDNA to the respiratory tract of individuals with cystic fibrosis. Nat Genet 1994; 8: 42-51.

12. Caplen NJ, Alton EWFW, Middleton PG, et al. Liposomemediated CFTR gene transfer to the nasal epithelium of patients with cystic fibrosis. Nat Med 1995; 1: 39-46.

13. Johnson LG, Olsen JC, Sarkadi B, Moore KL, Swanstrom $\mathrm{R}$, Boucher RC. Efficiency of gene transfer for restoration of normal airway epithelial function in cystic fibrosis. Nat Genet 1992; 2: 21-25.

14. Dorin JR, Farley R, Webb S, et al. A demonstration using mouse models that successful gene therapy for cystic fibrosis requires only partial gene correction. Gene Therapy 1996; 3: 797-801.

15. Stern M, Munkonge FM, Caplen NJ, et al. Quantitative fluorescence measurements of chloride secretion in native airway epithelium from $\mathrm{CF}$ and non-CF subjects. Gene Therapy 1995; 2: 766-774.

16. Renier M, Tamanini A, Nicolis E, et al. Use of a membrane potential-sensitive probe to assess biological expression of the cystic fibrosis transmembrane conductance regulator. Hum Gene Ther 1995; 6: 1275-1283.

17. Imundo L, Barasch J, Prince A, Al-Awqati Q. Cystic fibrosis epithelial cells have a receptor for pathogenic bacteria on their apical surface. Proc Natl Acad Sci USA 1995; 92: 3019-3023.

18. Pier GB, Grout M, Zaidi TS, et al. Role of mutant CFTR in hypersusceptibility of cystic fibrosis patients to lung infections. Science 1996; 271: 64-67.

19. Smith JJ, Travis SM, Greenberg EP, Welsh MJ. Cystic fibrosis airway epithelia fail to kill bacteria because of abnormal airway surface fluid. Cell 1996; 85: 229-236.

20. Caplen NJ, Kinrade E, Chakera A, et al. Gene therapy for cystic fibrosis in human subjects by liposome-mediated DNA transfer: regulatory process (in the UK) and production of resources. Gene Therapy 1994; 2: 1-9. 